\title{
Dexamethasone Injection Into Pterygomandibular Space Versus Sublingual Space on Post-Operative Sequalae of Lower Third Molar Intervention
}

\author{
Pimrampai Moranon ${ }^{\mathrm{a}}$, Teeranut Chaiyasamut ${ }^{\mathrm{b}}$, Watus Sakdajeyont ${ }^{\mathrm{b}}$, \\ Chakorn Vorakulpipat ${ }^{\mathrm{a}, \mathrm{d}}$, Boworn Klongnoi ${ }^{\mathrm{b}}$, \\ Sirichai Kiattavornchareon ${ }^{\mathrm{b}}$, Natthamet Wongsirichat ${ }^{\mathrm{b}, \mathrm{c}, \mathrm{d}}$
}

\begin{abstract}
Background: The surgical removal of lower third molar is still the most common surgical procedure that is done in oral and maxillofacial surgery field and creates the predictable post-operative sequelae such as pain, swelling, stiffness and difficulty in mouth opening. The purpose of this study is to compare pre-operative dexamethasone injection into pterygomandibular space (PGS) and sublingual space (SLS) in lower third molar intervention of post-operative pain, swelling, and limited mouth opening.

Methods: This study is the split-mouth, randomized crossover clinical trial in 30 healthy patients (mean age 21 years). These patients had similar bilateral lower third molar impactions. The patients were randomly divided into two groups receiving either 8-mg dexamethasone injection into SLS or PGS with the 4-week washout period intervention. Clinical assessment of facial swelling and maximum mouth opening was performed before operation and on day 2 and day 7 after operation. The post-operative pain was also measured by patients' response on pain visual analogue scale (VAS) on the first, second and third day after intervention.
\end{abstract}

Results: There is no significant difference between PGS group and

Manuscript submitted April 17, 2019, accepted May 4, 2019

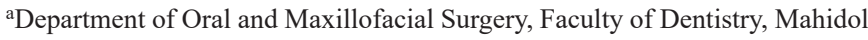
University, Bangkok 10400, Thailand

${ }^{\mathrm{b}}$ Thai Board of Oral and Maxillofacial Surgery, Department of Oral and Maxillofacial Surgery, Faculty of Dentistry, Mahidol University, Bangkok 10400, Thailand

${ }^{\mathrm{c} C o n s u l t a n t}$ of Walailak University International College of Dentistry, 19th floor SM Tower, 979/42-46 Phahonyothin Road, Phaya Thai District, Bangkok 10400, Thailand.

${ }^{\mathrm{d} C}$ Corresponding Author: Chakorn Vorakulpipat, German Board of Oral and Maxillofacial Surgery, Department of Oral and Maxillofacial Surgery, Faculty of Dentistry, Mahidol University, 6 Yothi Street, Rachathewee District, Bangkok 10400, Thailand. Email: chakorn.vor@mahidol.ac.th;; Natthamet Wongsirichat, Thai Board of Oral and Maxillofacial Surgery, Department of Oral and Maxillofacial Surgery, Faculty of Dentistry, Mahidol University, 6 Yothi Street, Rachathewee District, Bangkok 10400, Thailand.

Email: natthamet.won@mahidol.ac.th

doi: https://doi.org/10.14740/jocmr3844
SLS group in pain and swelling on the second and seventh day after operation. However, PGS group showed a greater degree of limited mouth opening than SLS group on the second day after operation.

Conclusions: This study showed that 8-mg dexamethasone injection into PGS or SLS was not different in reduction of pain, swelling, and limited mouth opening. This result suggests that dexamethasone injection into PGS or SLS is similarly effective.

Keywords: Lower third molar intervention; Dexamethasone injection; Sublingual space; Pterygomandibular space; Post-operative sequalae

\section{Introduction}

The removal of mandibular third molar (MTM) is the most common surgical procedure that is done by oral and maxillofacial surgeons and is associated with predictable complications such as post-intervention pain, swelling, limited mouth opening [1]. The region of intervention is composed of loose connective tissue that contains blood and lymph vessels, and may cause post-operative sequelae. The post-operative pain begins when the effect of the local anesthesia subsides and reaches its maximum intensity during the first $12 \mathrm{~h}$ post-operatively. The large varieties of analgesics are available for management of post-operative pain. Limited mouth opening is a normal and expected outcome following third molar intervention, and usually reaches its peak on the third day and relieves in the first week [2]. This post-operative complication brought by MTM intervention usually causes discomfort feeling for patients that can impact their quality of life, which should be minimized as much as possible.

Post-operative events are usually treated with pharmacological strategy. Corticosteroid such as dexamethasone is known to reduce inflammation, fluid transudation and edema [3]. Dexamethasone has been used extensively in oral and maxillofacial surgery due to the glucocorticoid effects, absence of mineralocorticoid effects, and the least adverse effects on leukocyte chemotaxis $[1,4]$. Glucocorticoids inhibit capillary 
permeability, bronchoconstriction, and inhibit vascular and inflammatory responses [5]. Dexamethasone is being delivered for third molar intervention by many routes such as oral consumption, intravenous, intramuscular delivery in masseter, gluteal or deltoid region, sub-mucosal injection, endoalveolar powder and delivery into the potential space.

The previous studies mentioned the use of dexamethasone to reduce the complication following MTM intervention. The previous research of Grossi et al [6] studied the effect of submucosal injection of dexamethasone on post-operative third molar intervention. The study of Alcantara et al [7] also found that pre-operative dexamethasone in facial swelling control and limited mouth opening had better effect than $40 \mathrm{mg}$ methylprednisolone. The previous research of Mojsa et al [8] also studied the effect of dexamethasone on three groups of facial swelling, post-operative pain and limited mouth opening following third molar intervention, and post-operative pain and limited mouth opening after removal of impacted lower third molar. The previous study of Antonio et al [9] mentioned that the oral administration and local injection in the masseter muscle of $8 \mathrm{mg}$ dexamethasone proved effective in reducing postoperative pain, edema, and limited mouth opening following lower third molar intervention. The research of Chaurand-Lara and Facio-Umana [10] which studied the effect of administration of $20 \mathrm{mg}$ methylprednisolone intramuscularly in masseter mentioned post-operative facial swelling and post-operative pain after surgical removal of impacted lower third molars. However, the previous study of Tiigimae-Saar et al [11] also found that a combination of a single dose of prednisolone and etorikoxib is suitable for treatment of post-operative pain, limited mouth opening, and swelling after third molar intervention.

The previous research of Tiwana et al [12] studied intravenous corticosteroids before third molar intervention without antibiotics in patients at high risk for delayed health-related quality of life and clinical recovery, and found intravenous corticosteroid administration had a limited, but beneficial effect on health-related quality of life outcomes. The previous article of Ehsan et al [13] found that $4 \mathrm{mg}$ submucosal dexamethasone injection before surgical removal of MTM also significantly reduced post-operative swelling and limited mouth opening. The previous study of Bauer et al [14] found that the pre-emptive analgesia with ibuprofen was also insufficient to inhibit central sensitization, but dexamethasone was more effective to prevent post-operative pain in third molar intervention. The previous study of Baxendale et al [15] found that dexamethasone significantly reduced post-operative pain $4 \mathrm{~h}$ after MTM intervention and reduced the use of opioid analgesics, and dexamethasone could also reduce swelling significantly, but there was no effect on limited mouth opening. The study of Li et al [16] assessed the efficacy of dexamethasone in pericoronal injection for controlling post-operative swelling and limited mouth opening caused by impacted MTM intervention. Periodontal injection of $4-5 \mathrm{mg}$ could control post-operative facial swelling and limited mouth opening following impacted MTM intervention. The previous article of Filho et al [2] showed that the administration of $4 \mathrm{mg}$ versus $8 \mathrm{mg}$ dexamethasone, and $8 \mathrm{mg}$ dexamethasone was more effective to control post-operative swelling and limited mouth opening than $4 \mathrm{mg}$ in mandibular impacted third molar inter- vention.

There are many routes of dexamethasone administration for research of mandibular impacted third molar intervention outcomes. The previous study of Latt et al [17] studied the efficacy of dexamethasone injection versus the saline injection (control group) on post-operative pain in lower third molar intervention. The previous study of Gozali et al [18] also mentioned the decreased post-operative pain using 8-mg dexamethasone injection into sublingual space (SLS) compared with the saline group in lower third molar intervention.

The benefit of the two routes is that no additional postoperative pain is caused to patient when injected after inferior alveolar nerve block, lingual nerve block and long buccal nerve block that is commonly done in dentistry of MTM intervention. This technique is simple and can be done easily for the dentist. Other techniques, such as intravenous or intramuscular delivery, require mastering additional techniques and cause post-operative pain to patient during injection.

On the other hand, there is no further study about dexamethasone injection into pterygomandibular space (PGS) versus into SLS. Therefore, this current research studied 8-mg dexamethasone injection into PGS versus SLS to control post-operative pain, facial swelling and limited mouth opening. The benefit of this study is to improve the patient's quality of life after intervention of MTM in simple lifestyle, safety, painless and less cost-effective therapeutic option.

\section{Materials and Methods}

The Oral and Maxillofacial Surgery Clinic of the Faculty of Dentistry, Mahidol University, Thailand is the address for this prospective randomized controlled split-mouth clinical crossover study. Every author of this study has ORCID iD and the protocol of this investigation was approved by the research ethics committee of Mahidol University Institutional Review Board (COA No. MU-DT/PY-IRB 2016/021.2303), and written informed consent (local language) was obtained from all the patients before intervention.

\section{Sample size calculation}

Sample size calculation has been performed by using $\mathrm{G}$ power 3.1 .0 software, assuming $\alpha$ error is 0.05 , power is $95 \%$ and estimated effect size is 0.4 . After our pilot study we calculated our sample size following the related formula recommendations. Minimum sample size must be at least 25 adult patients and withdrawal of five patients. There was no withdrawal in this study, so this study included 30 patients. The patients have been informed of the procedures and objectives of the study and inform consent has been obtained.

This current research included 30 healthy patients (13 men, 17 women) on eligibility criteria selection as shown in Table 1, with an average age of 21 years (age range $16-31$ years), with similar bilateral lower third molar and the same degree of positions (Table 2 and Fig. 1). The surgical removal 
Table 1. Eligibility Criteria Selection of the Patients

\section{Inclusion criteria selection of the patients}

The patient has bilateral impacted lower third molars symmetrically positioned on both sides of the mandible of which surgical removal consists of flap operation, bone removal, and tooth section

Aged between 18 - 45 years

No history of allergy to dexamethasone, amoxicillin, or acetaminophen

No use of other medicine 1 month before and during the study period

The patient is able to understand and carry out the instructions given by the investigators

The patient has provided their consent for the study

\section{Exclusion criteria selection of the patients}

Pregnancy or current lactation

Patients with cardiovascular problems, renal and/or liver failure, or other serious medical conditions

Allergic to local anesthetics and other drugs that were used in this study

Patient with facial deformities that may interfere with the injections, surgery or evaluation

The existence of acute infection and/or swelling and pain at the time of surgery

Patients taking any medication during the previous 1 month prior to the surgery

Inability to follow the instructions or cooperate during the study

Duration of treatment more than $1 \mathrm{~h}$

consisted of bone cut and tooth section. Patient had not used other medicines 1 month before the intervention, and had no history of allergy to drug used in this study.

This crossover research had spilt-mouth design by injection of $8 \mathrm{mg}$ of dexamethasone into SLS and PGS on another side. Each patient appointed for two different surgical procedures by the same experienced surgeon (SLS injection and PGS injection). The washout period of the second appointment was 4 weeks after first intervention. The patients were blinded of 8-mg dexamethasone injection after inferior alveolar nerve block and were in a state of complete numbness [19-20], $8 \mathrm{mg}$ of dexamethasone was injected, and then standard technique of lower third molar intervention was performed.

Table 2. Demographic Data of Patients in Study Groups

\begin{tabular}{|c|c|c|c|c|}
\hline \multirow{2}{*}{ Data consideration } & \multicolumn{2}{|c|}{$8 \mathrm{mg}$ dexamethasone } & \multirow{2}{*}{ Total } & \multirow{2}{*}{ Percentage } \\
\hline & Pterygomandibular space injection & Sublingual space injection & & \\
\hline Number & 30 & 30 & 60 & 100 \\
\hline \multicolumn{5}{|l|}{ Age } \\
\hline $16-25$ years & 28 & 28 & 56 & 93.3 \\
\hline $26-32$ years & 2 & 2 & 4 & 6.6 \\
\hline Male & 13 & 13 & 26 & 43.3 \\
\hline Female & 17 & 17 & 34 & 56.7 \\
\hline \multicolumn{5}{|l|}{ Position } \\
\hline A & 9 & 9 & 18 & 30 \\
\hline B & 21 & 21 & 42 & 70 \\
\hline
\end{tabular}

Position A: the part of the lower third molar is above the occlusal plane of the lower second molar; Position B: the highest portion of the lower third molar is between the occlusal plane and the cervical line of the second molar; Class I: there is sufficient space of accommodation of the mesio-distal diameter of the lower third molar; Class II: the space of accommodation of the mesio-distal diameter of the lower third molar is less than the mesiodistal diameter of the lower third molar. 

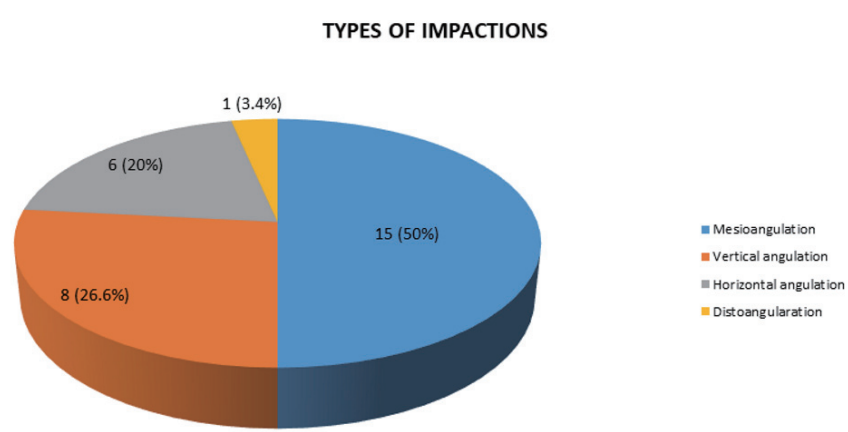

Figure 1. Types of impactions in the patients of this research study.

\section{Eligibility criteria of patient's selection}

Demographic data of each patient has been recorded (including name, sex, age, patient profiles, medical history, and dental history). Current and previous medical and dental history has been noted and compliance with the inclusion and exclusion criteria was established.

According to the withdrawal criteria, the patients can withdraw their participation in this research at any time depending on their own decision but no anyone withdrew.

\section{Clinical measurements}

Patient will be measured for post-operative pain, swelling and limit mouth opening on the day before intervention and on second and seventh day post-operatively with same technique as the pre-operative one by same examiner: 1) Post-operative pain assessment by visual analogue scale (VAS) scores [20-22] and the number of analgesic tablets required; 2) Facial swelling [17-18] was measured by facial contour by using three lines along the length of the face from the reference point, lateral corner of eye to angle of mandible, corner of mouth to border of earlobe, soft tissue pogonion to border of earlobe (Fig. 2); and 3) Limited mouth opening [17-18] was measured along the distance between incisal edge of maxillary and mandibular incisor (inter-incisal distance).

\section{Statistical analysis of the data research}

The Statistical Package for the Social Sciences (SPSS version 22, SPSS Inc., Chicago, IL, USA) was used to calculate the significance of differences between two groups. Descriptive statistical parameters (mean, standard deviation, and independent-sample $t$-test) were used to assess the significance of difference. $\mathrm{P}<0.05$ was considered significant.

\section{Results}

There were a total of 60 lower third molar removals involving 30 interventions with dexamethasone injection in SLS group and PGS group. Table 3 showed the duration of operation time

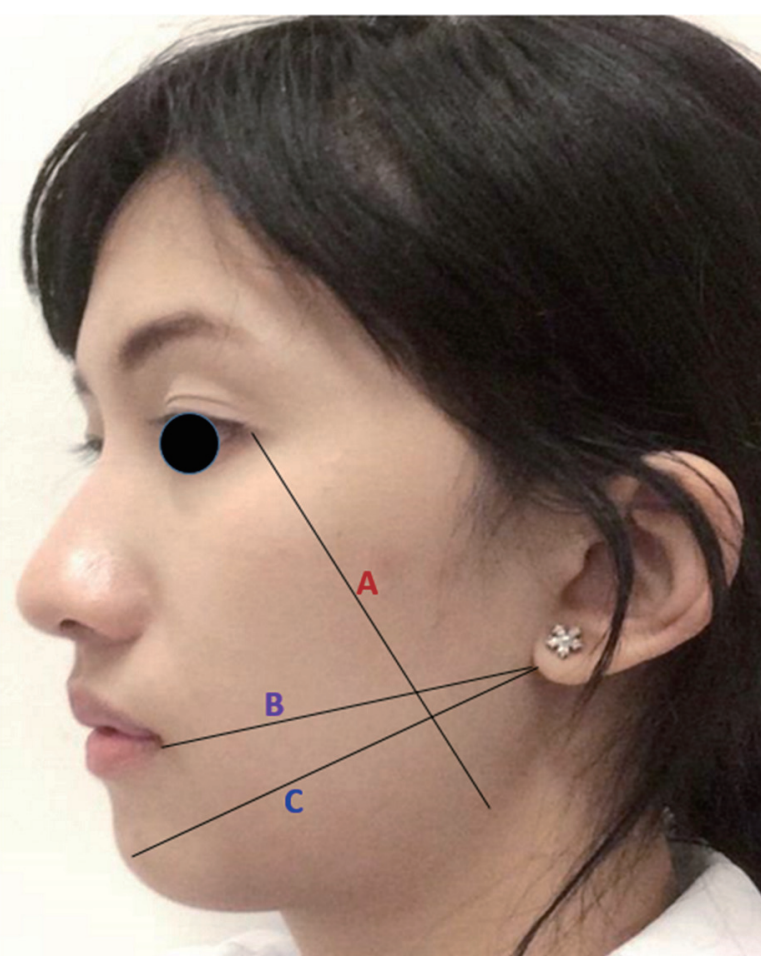

Figure 2. Three reference lines for facial length measurement. A: lateral corner of eye to angle of mandible; $\mathrm{B}$ : corner of mouth to border of earlobe; C: soft tissue pogonion to border of earlobe.

was 19.9 in PGS group and 20.5 in SLS group. There was no significant difference between duration of intervention. In this study, no post-operative complication was found in both groups.

The evaluation of post-operative pain based on $100-\mathrm{mm}$ VAS was not significantly different in immediately intervention, day 1, day 2 and day 7 between both groups, and analgesic taking for post-operative pain was not significantly different on all post-operative days between control and test groups as shown in Table 4. Table 5 showed no significant increase in post-operative facial swelling on the second and seventh postoperative days compared with pre-operatively in both groups by measurement of tragus to commissure of mouth, tragus to pogonion, and gonial angle to lateral canthal of eye.

Measurements of limited mouth opening were significantly different $(\mathrm{P}=0.004)$ on the second post-operative day and different between baseline and second post-operative day. Measurements of limited mouth opening were significantly different between two groups $(\mathrm{P}=0.004)$. But on the seventh post-operative day there was no significant different (Table 6).

\section{Discussion}

MTM impaction is a common problem affecting a large proportion of population. The surgical removal of MTM is associated with many post-operative sequelae as post-operative facial swelling, post-operative pain and limited mouth opening. When the tissues are injured, the normal physiologic response 
Table 3. Duration of Mandibular Third Molar Intervention of the Patients in Study Groups

\begin{tabular}{lll}
\hline \multirow{2}{*}{ Data consideration } & \multicolumn{2}{c}{$\mathbf{8 ~ m g ~ d e x a m e t h a s o n e ~}$} \\
\cline { 2 - 3 } & Pterygomandibular space injection (SD) & Sublingual space injection (SD) \\
\hline Duration of operation $(\mathrm{min})$ & $19.93(2.71)$ & $20.50(2.77)$ \\
\hline
\end{tabular}

Table 4. Measurements of Post-Operative Pain (VAS in Millimeters and Number of Analgesic Taken in Number of Tablets) in Study Groups

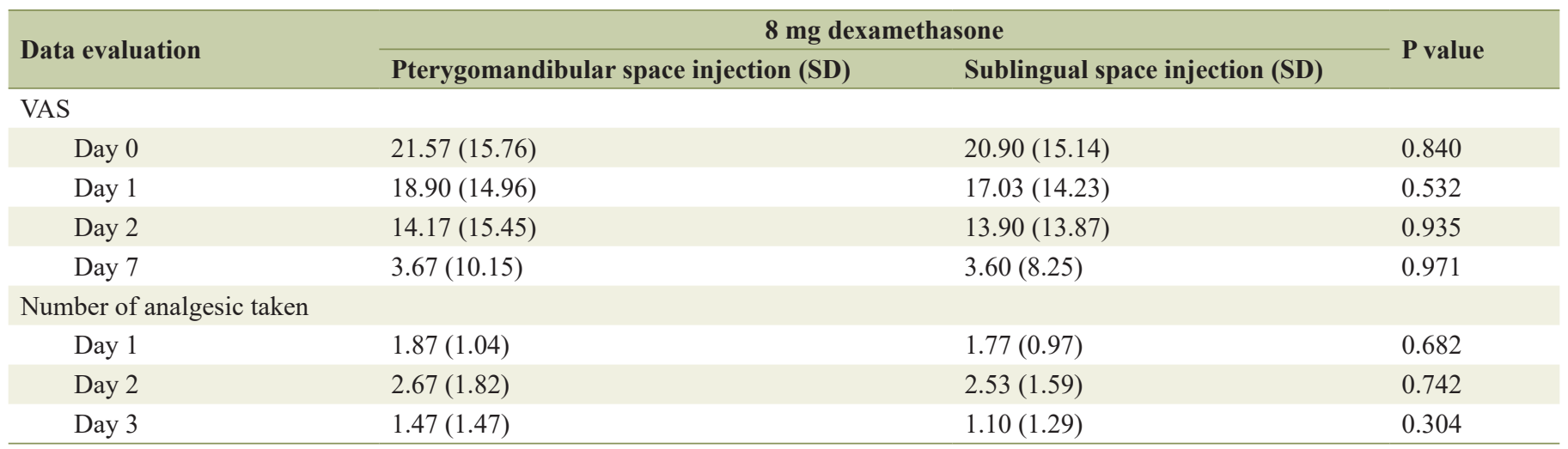

Day 0: immediate after operation; Day 1: first day after operation; Day 2: second day after operation; Day 3: third day after operation; Day 7: seventh day after operation.

Table 5. Swelling Measurements and Differences in Millimeters From Baseline Value in Study Groups

\begin{tabular}{|c|c|c|c|}
\hline \multirow{2}{*}{ Data evaluation } & \multicolumn{2}{|c|}{$8 \mathrm{mg}$ dexamethasone } & \multirow{2}{*}{ P value } \\
\hline & Pterygomandibular space injection, mean (SD) & Sublingual space injection, mean (SD) & \\
\hline \multicolumn{4}{|l|}{ Tr-Com } \\
\hline Second day & $118.83(6.84)$ & $118.66(6.01)$ & 0.724 \\
\hline Seventh day & $116.56(6.85)$ & $116.53(6.22)$ & 0.926 \\
\hline Seventh day-baseline & $1.46(2.14)$ & $1.50(1.50)$ & 0.926 \\
\hline \multicolumn{4}{|l|}{ Tr-Pog } \\
\hline Baseline & $115.10(6.05)$ & $115.03(6.12)$ & 0.326 \\
\hline Second day & $118.83(6.84)$ & $118.66(6.01)$ & 0.724 \\
\hline Seventh day-baseline & $1.46(2.14)$ & $1.50(1.50)$ & 0.926 \\
\hline \multicolumn{4}{|l|}{ Gn-Lc } \\
\hline Baseline & $106.86(8.52)$ & $105.6(7.92)$ & 0.99 \\
\hline Second day & $110.83(8.02)$ & $109.53(7.65)$ & 0.177 \\
\hline Seventh day & $108.56(8.16)$ & $107.26(7.77)$ & 0.115 \\
\hline \multicolumn{4}{|l|}{ Differences } \\
\hline Second day-baseline & $3.96(2.57)$ & $3.93(2.11)$ & 0.954 \\
\hline Seventh day-baseline & $1.7(2.56)$ & $1.6(2.13)$ & 0.897 \\
\hline
\end{tabular}

Tr-Com: tragus-commissure of mouth; Tr-Pog: tragus-pogonion; Gn-Lc: goial angle-lateral canthal of eye. 
Table 6. Measurements of Limited Mouth Opening and Differences in Millimeters From Baseline Value in the Study Groups

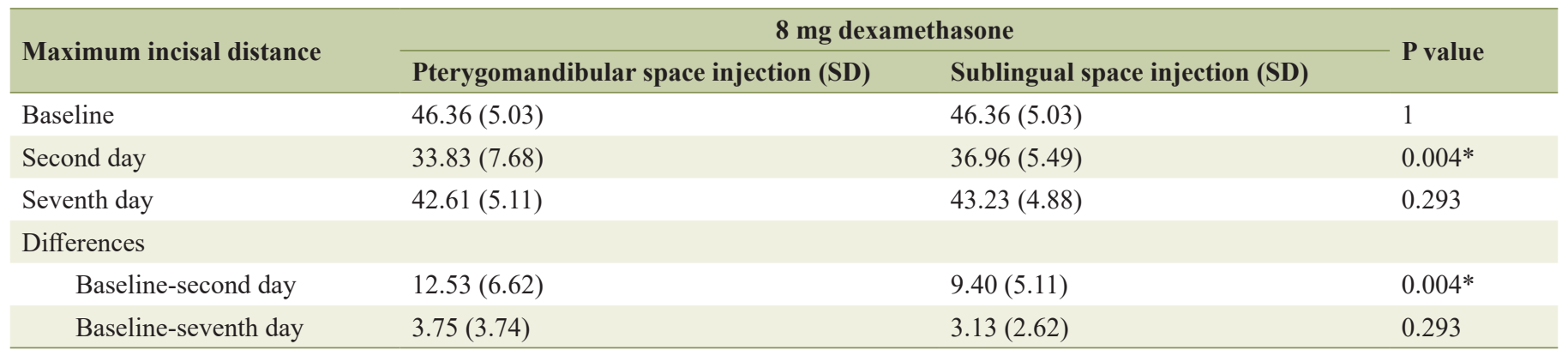

${ }^{*} \mathrm{P}<0.01$

Table 7. The Summary of Previous Studies of Dexamethasone

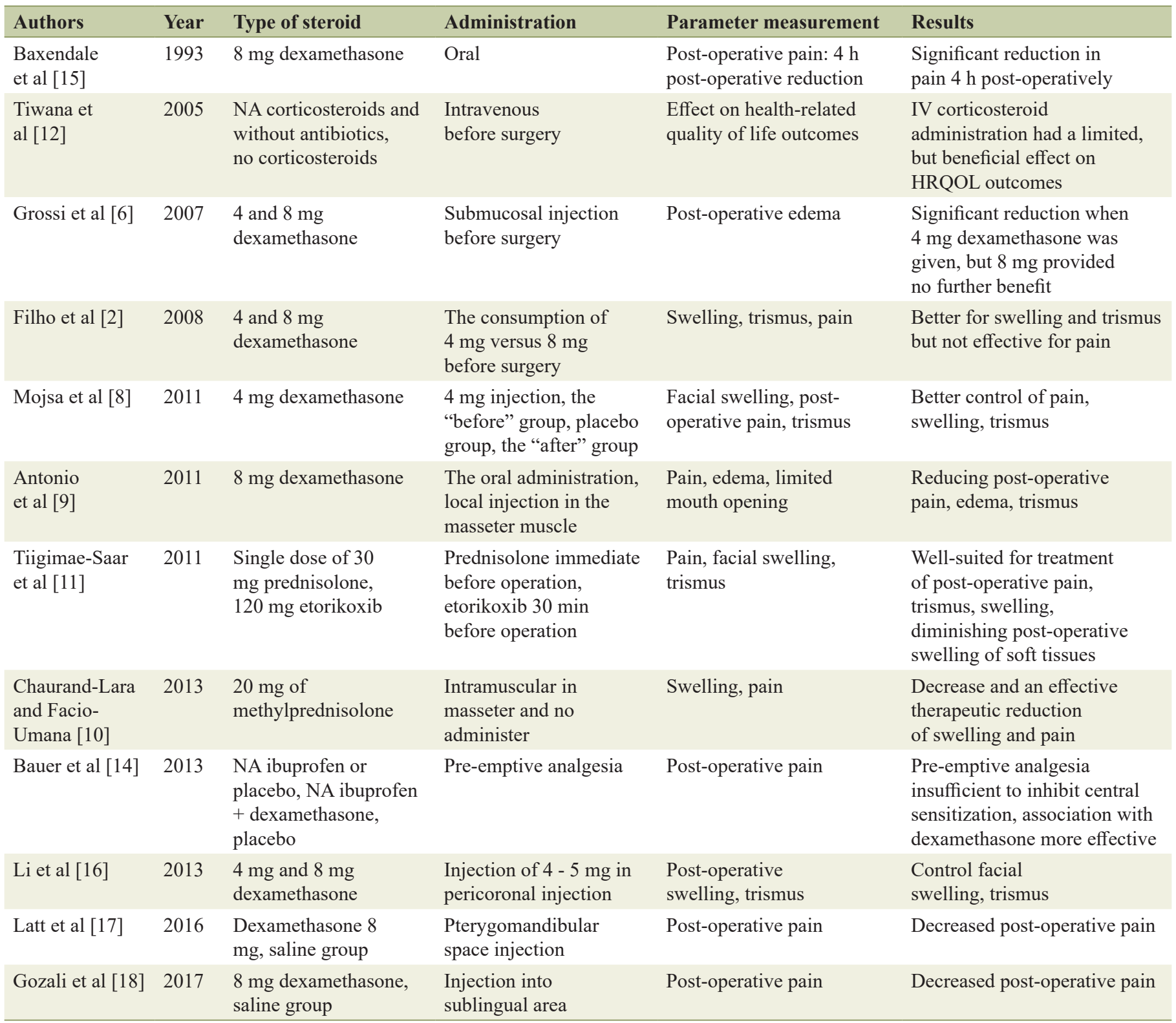

NA: unknown; HRQOL: health-related quality of life; IV: intravenous. 
is inflammation, leading to post-operative pain and swelling. Experience of surgeons and difficulty of lower third molar surgery are recognized as significant factors in the incidence and severity of post-operative sequelae.

Corticosteroids have been shown to reduce level of lymphokine, prostaglandin, serotonin, bradykinin, cortisol, migratory inhibiting factor, and $\beta$-endorphin and are believed to decrease post-operative facial swelling and limited mouth opening [17-18]. Many previous literatures proved that preoperative dexamethasone injection had benefit in reducing post-operative complication in lower third molar intervention. All routes of administration lead to similar result because of systemic effect of steroid. All steroids must be administered before the infliction of tissue damage, not during or after intervention [23-25]. It caused peak level of bradykinin release occurring within $3 \mathrm{~h}$ after tissue trauma. Gersema and Baker [26] and Milles and Desjardins [27] concluded that steroid was unable to reduce the post-operative pain significantly.

Filho et al [2] administered $8 \mathrm{mg}$ of dexamethasone, which was reported to be more effective than $4 \mathrm{mg}$. It is equal to the $200 \mathrm{mg}$ of cortisol.

In the previous studies or research dexamethasone is being delivered for third molar intervention by many routes such as oral consumption, intravenous, intramuscular delivery in masseter, gluteal or deltoid region, sub-mucosal injection, and delivery into the potential space as shown in Table $7[2,6,8$ 12, 14-18].

In this study, we injected dexamethasone into SLS and PGS as we believed that it is more convenient for the patient compared to intramuscular, intravenous delivery and deep intra-potential space injection, because patient will have numbness at this area after local anesthesia. The SLS is considered as superficial potential sites for drug administration. SLS injection is characterized by systemic administration, high permeability and rich blood supply.

Our project as the previous study of Gozali et al [18] found that $8 \mathrm{mg}$ dexamethasone injected into SLS in lower third molar intervention offered several advantages: less postoperative pain (VAS pain score and analgesic consumption), wider maximum mouth opening, and less swelling compared to saline injection as compared to control group. However, the previous research of Latt et al [17] found that injection of $8 \mathrm{mg}$ dexamethasone into the PGS also effectively reduced the postoperative swelling, limited mouth opening and post-operative pain in lower third molar intervention compared to the saline group.

In this split-mouth, crossover study, dexamethasone was injected into SLS and PGS after onset of local anesthesia. The duration of operation in this study was not significantly different between both groups, with same position and type of impacted lower third molar and by the same operator (Table 3). Post-operative facial swelling was evaluated by measuring three linear facial distances which was a non-invasive, simple, cost-effective and time-saving method. Post-operative pain was evaluated by VAS and number of analgesic taken, and limited mouth opening was measured by interincisal distance. This current study found that there is no significant difference between both groups because of the systemic effect of corticosteroid. Nonetheless PGS group showed a greater degree of limited mouth opening than SLS group on day 2 after operation because the technique of injection may cause trauma and maybe because of the large volume of drug injected, but it will improve on day 7 after operation. In this study, no post-operative complication was found in both groups.

In conclusion, significant dexamethasone injection in lower third molar intervention can decrease post-operative pain and swelling. This research studied PGS and SLS groups of dexamethasone injection. The injection in both groups had advantage that no pain appeared during dexamethasone administration, and there was no difference in post-operative pain and post-operative facial swelling, but PGS group had greater degree of post-operative limited mouth opening on day 2 after operation than SLS group. The suggestion from this study for the dentists is using 8-mg dexamethasone injection into both PGS and SLS.

\section{Acknowledgments}

The authors would like to thank the staff and dental assistants including colleagues and co-workers in the Department of Oral and Maxillofacial Surgery, Faculty of Dentistry, Mahidol University.

\section{Financial Disclosure}

There is no funding.

\section{Conflict of Interest}

The authors declare no conflict of interest.

\section{Informed Consent}

Written informed consent (local language) was obtained from all the patients before intervention.

\section{Author Contributions}

NW contributed to conceptualization; TC and WS contributed to methodology; PM contributed to validation and investigation; PM and WS contributed to formal analysis; WS contributed to resources; SK was involved in data curation; PM, WS and SK contributed to original draft preparation; BK and NW were involved in reviewing and editing of the manuscript; TC, NW and BK contributed to visualization and supervision; $\mathrm{CV}$, NW and SK were involved in project administration.

\section{References}

1. Peterson LJ. Principles of management of impacted teeth. In: Peterson LJ, ed. Principles of oral and maxillofacial 
surgery. Vol 1. Philadelphia: JB Lippincott. 1992; p. 117.

2. Laureano Filho JR, Maurette PE, Allais M, Cotinho M, Fernandes C. Clinical comparative study of the effectiveness of two dosages of Dexamethasone to control postoperative swelling, trismus and pain after the surgical extraction of mandibular impacted third molars. Med Oral Patol Oral Cir Bucal. 2008;13(2):E129-132.

3. Neupert EA, 3rd, Lee JW, Philput CB, Gordon JR. Evaluation of dexamethasone for reduction of postsurgical sequelae of third molar removal. J Oral Maxillofac Surg. 1992;50(11):1177-1182; discussion 1182-1173.

4. Montgomery MT, Hogg JP, Roberts DL, Redding SW. The use of glucocorticosteroids to lessen the inflammatory sequelae following third molar surgery. J Oral Maxillofac Surg. 1990;48(2):179-187.

5. John AY, Frank JD, Barton SJ, Angelo J, Enid AN. Pharmacology and the therapeutic for dentistry, 6th ed. St Louis, CV Mosby. 2011;615.

6. Grossi GB, Maiorana C, Garramone RA, Borgonovo A, Beretta M, Farronato D, Santoro F. Effect of submucosal injection of dexamethasone on postoperative discomfort after third molar surgery: a prospective study. J Oral Maxillofac Surg. 2007;65(11):2218-2226.

7. Alcantara CE, Falci SG, Oliveira-Ferreira F, Santos CR, Pinheiro ML. Pre-emptive effect of dexamethasone and methylprednisolone on pain, swelling, and trismus after third molar surgery: a split-mouth randomized triple-blind clinical trial. Int J Oral Maxillofac Surg. 2014;43(1):9398.

8. Mojsa IM, Pokrowiecki R, Lipczynski K, Czerwonka D, Szczeklik K, Zaleska M. Effect of submucosal dexamethasone injection on postoperative pain, oedema, and trismus following mandibular third molar surgery: a prospective, randomized, double-blind clinical trial. Int J Oral Maxillofac Surg. 2017;46(4):524-530.

9. Antunes AA, Avelar RL, Martins Neto EC, Frota R, Dias E. Effect of two routes of administration of dexamethasone on pain, edema, and trismus in impacted lower third molar surgery. Oral Maxillofac Surg. 2011;15(4):217223.

10. Chaurand-Lara J, Facio-Umana J. Methylprednisolone injection following the surgical extraction of impacted lower third molars: A split-mouth study. Open Journal of Stomatology. 2013;3:192-196.

11. Tiigimae-Saar J, Leibur E, Tamme T. The effect of prednisolone on reduction of complaints after impacted third molar removal. Stomatologija. 2010;12(1):17-22.

12. Tiwana PS, Foy SP, Shugars DA, Marciani RD, Conrad SM, Phillips C, White RP. The impact of intravenous corticosteroids with third molar surgery in patients at high risk for delayed health-related quality of life and clinical recovery. J Oral Maxillofac Surg. 2005;63(1):55-62.

13. Ehsan A, Ali Bukhari SG, Ashar, Manzoor A, Junaid M. Effects of pre-operative submucosal dexamethasone injection on the postoperative swelling and trismus following surgical extraction of mandibular third molar. J Coll Physicians Surg Pak. 2014;24(7):489-492.
14. Bauer HC, Duarte FL, Horliana AC, Tortamano IP, Perez FE, Simone JL, Jorge WA. Assessment of preemptive analgesia with ibuprofen coadministered or not with dexamethasone in third molar surgery: a randomized doubleblind controlled clinical trial. Oral Maxillofac Surg. 2013;17(3):165-171.

15. Baxendale BR, Vater M, Lavery KM. Dexamethasone reduces pain and swelling following extraction of third molar teeth. Anaesthesia. 1993;48(11):961-964.

16. Li C, Zhao H, Li L, Li S, Wu Y, Liao X, Pan J. [Systematic review on control of swelling and trismus after extraction of impacted mandibular third molar by dexamethasone pericoronal injection]. Hua Xi Kou Qiang Yi Xue Za Zhi. 2013;31(3):267-271.

17. Latt MM, Kiattavorncharoen S, Boonsiriseth K, Pairuchvej V, Wongsirichat N. The efficacy of dexamethasone injection on postoperative pain in lower third molar surgery. J Dent Anesth Pain Med. 2016;16(2):95-102.

18. Gozali P, Boonsiriseth K, Kiattavornchareon S, Khanijou M, Wongsirichat N. Decreased post-operative pain using a sublingual injection of dexamethasone $(8 \mathrm{mg})$ in lower third molar surgery. J Dent Anesth Pain Med. 2017; 17(1):47-53.

19. Raocharernporn S, Boonsiriseth K, Khanijou M, Wongsirichat N. Hemodynamic changes and pain perceptionrelated anxiety after experiencing an impacted-tooth removal: clinical practice outcome. J Dent Anesth Pain Med. 2017;17(2):105-111.

20. Boonsiriseth K, Chaimanakarn S, Chewpreecha P, Nonpassopon N, Khanijou M, Ping B, Wongsirichat N. 4\% lidocaine versus $4 \%$ articaine for inferior alveolar nerve block in impacted lower third molar surgery. J Dent Anesth Pain Med. 2017;17(1):29-35.

21. Sirintawat N, Sawang K, Chaiyasamut T, Wongsirichat N. Pain measurement in oral and maxillofacial surgery. J Dent Anesth Pain Med. 2017;17(4):253-263.

22. Ping B, Kiattavorncharoen S, Saengsirinavin C, Im P, Durward C, Wongsirichat N. The efficacy of an elevated concentration of lidocaine $\mathrm{HCl}$ in impacted lower third molar surgery. J Dent Anesth Pain Med. 2015;15(2):6976.

23. Pedersen A. Decadronphosphate in the relief of complaints after third molar surgery. A double-blind, controlled trial with bilateral oral surgery. Int J Oral Surg. 1985;14(3):235-240.

24. Ucok C. Stereophotogrammetric assessment of the effect of tenoxicam on facial swelling subsequent to third molar surgery. Int J Oral Maxillofac Surg. 1997;26(5):380-382.

25. Beirne OR, Hollander B. The effect of methylprednisolone on pain, trismus, and swelling after removal of third molars. Oral Surg Oral Med Oral Pathol. 1986;61(2):134138.

26. Gersema L, Baker K. Use of corticosteroids in oral surgery. J Oral Maxillofac Surg. 1992;50(3):270-277.

27. Milles M, Desjardins PJ. Reduction of postoperative facial swelling by low-dose methylprednisolone: an experimental study. J Oral Maxillofac Surg. 1993;51(9):987-991. 